\title{
RANDOM REFLECTIONS ON A HUMAN MILK BANK
}

\author{
BY \\ J. GREENWOOD WILSON \\ From the Welsh National School of Medicine
}

During the past 30 years a considerable volume of literature has accumulated on the composition of and the nutritive qualities of both human and cow's milk. A number of ad hoc sampling surveys of human milk has been carried out, notably those reported on by Kon and Mawson (1950), but the establishment of human milk bureaux or human milk banks has offered the opportunity of studying analyses of a number of human milk samples not taken specifically for the purposes of any ad hoc investigation, but examined in the course of the routine administration of the milk bank service.

The milk bank is a mechanical device for pooling, pasteurizing, and, if necessary, storing milk received from milk donors who have more than enough milk to spare.

The first milk bank to be established on a big scale in this country was at Queen Charlotte's Hospital, London. It owed its inspiration to the former matron, Miss E. G. Dare, who, in 1944, was good enough to visit Cardiff to explain to the municipal authorities its purpose and organization. Despite war-time and post-war difficulties of materials, licensing, and controls, the Cardiff City Council at last succeeded in opening in 1947 the first municipal human milk bank in this country. It was modelled entirely on the one at Queen Charlotte's Hospital.

It is not so long ago that the wet-nurse was a recognized social institution in this country. It would be interesting to know how many of our surviving elders and betters received their earliest nourishment in that way. The individual wet-nurse is no more, but the idea has its modern counterpart in the form of the human milk bank which is essentially a mechanized wet-nurse that can feed not one, but hundreds of babies on breast milk.

Mothers in St. David's Hospital, where most of the hospital confinements in Cardiff take place, are selected before leaving hospital when it is thought that they will be able to provide breast milk in excess of that needed by their'own babies. It is often an advantage to mother and child to draw off the excess milk remaining after each feed, because it avoids discomfort to the mother and overfeeding the baby. Selected mothers are supplied with apparatus which they are trained to use at home.

For the purpose of what follows, it is important to emphasize that human milk donors are selected while they are still in the maternity wards of the St. David's Hospital, and that they are thoroughly trained before they leave hospital in the technique of full manual expression of their breast milk. It is contended that with this groundwork training, and with the constant practise that follows, they are bound to secure a more efficient expression of their breast milk than the mothers who assisted in ad hoc investigations like those reported by Kon and Mawson (1950). The Cardiff mothers so trained on their return home express all the breast milk that remains, after infant feeding, into an aluminium jug whence they pour it into medicine bottles. These they place in ice-box containers with which they have been provided in advance, and which are then ready for collection by the sister in charge of the milk bank.

Human milk donors are chosen from clean, sanitary homes, and have a complete physical examination before being accepted. Tuberculosis, syphilis, gonorrhoea and anaemia must be excluded particularly. The mother must be nursing her baby, and have a surplus after her baby has been fed. The baby's record is kept by the sister who collects the milk, and it is weighed at least once a month at a clinic. Homes of donors are also under observation by the health visitors, if only to protect the interest of those sucklings whose mothers might be tempted partially to wean them prematurely in order to have more milk to sell to the milk bank.

If the mother or baby is taken ill, collecting ceases for the time being, and the mother is advised to draw off and throw away the surplus until the illness is cleared up. Milk can be taken up to nine months provided that the baby has not been completely weaned.

Each mother's milk is tested by the city analyst for the addition or substitution of cow's milk, and is also analysed for its nutrient content.

The entire supply from all donors is pasteurized by a simple process. (All milk sent out from the milk bank is marked to indicate that at least $2 \mathrm{oz}$. of orange juice must be given daily to the baby because of the destruction of vitamin $\mathrm{C}$ by pasteurization.) All surplus from current use is frozen. The milk is not frozen in the bottles because it would take too 
long to melt back when needed. Instead, it is poured into the 10 shallow depressions on each freezing plate, each of which holds about one-third of an inch. The milk is pasteurized before freezing and every care is taken to avoid contaminating the milk. The frozen milk discs are sometimes jocularly described as peppermint creams. All apparatus is sterilized before use, and the nurse wears a mask while at work. The frozen milk discs can be kept for as long as six to 11 months in a special deep freeze apparatus, but there is also an ordinary domestic type refrigerator for short-time storage.

The maximum turnover of the Cardiff Milk Bank in any one week has been 278 pints. The milk is sent all over Great Britain to children's hospitals without depriving any local babies of their needs for human milk of this kind. The maximum earnings of a milk donor in any one week have been $£ 28 \mathrm{~s} .10 \mathrm{~d}$. (293 oz. at 2d. per oz.). This figure works out at a little more than 2 pints a day so that with the amount required for her infant this mother must have been producing a good 4 pints of milk a day. (Hutchison and Mottram (1936) say that a healthy woman produces $1 \frac{1}{2}$ to 4 pints a day, but averages $1 \frac{1}{2}$ pints.)

The pooled pasteurized milk from the milk bank is sampled daily for bacteriological contamination. The result is invariably less than 20 organisms per $\mathrm{ml}$.

Analyses of human milk supplied to the Cardiff Human Milk Bank have shown enormous variations in the fat content, not only as between the milk of one mother and another, but in that of the same mother almost from hour to hour in the same period of 24 hours' observation. Yet, the clinicians could not detect the slightest effect on the digestion or nutrition of the babies who consumed the milk. When the fat content of the milk of its mother went down, there was no apparent ill-effect on that baby's nutrition, and baby X, suckling from a mother with a persistently low milk fat content, did not seem to fare any worse than baby $Y$, suckling from a mother whose milk was rich in fat content.

I reproduce below some typical analyses to illustrate my point:-

$\begin{array}{ccccc}\begin{array}{c}\text { March 16, } 1948 \\ \text { Mrs. H. }\end{array} & \text { Fat } & \begin{array}{c}\text { Non-fatty Solids } \\ 8.94\end{array} & \begin{array}{c}\text { Total } \\ \text { Solids } \\ 9 \cdot 99 \%\end{array} \\ \begin{array}{c}\text { June 24, 1948 } \\ \text { Mrs. M. }\end{array} & \ldots & 7 \cdot 25 & 8 \cdot 87 & 16 \cdot 12 \%\end{array}$

To check this surprisingly high fat content further samples were taken with results as follows:-

\begin{tabular}{|c|c|c|}
\hline $\begin{array}{l}\text { Mrs. M. } \\
\text { Mrs. M. }\end{array}$ & $\begin{array}{rr} & \text { Fat } \\
\ldots & 4 \cdot 75 \\
\ldots & 4.57\end{array}$ & $\begin{array}{c}\text { Non-fatty Solids } \\
8 \cdot 89 \\
8 \cdot 85\end{array}$ \\
\hline
\end{tabular}

It will be noted that although subsequent samples showed a drop in the fat content this mother's milk was still of a higher fat content than the average.

Commenting on Mrs. M., whose first sample yielded a figure of $7 \cdot 25 \%$ for fat content, the clinician wrote: "The baby is doing very well and the birth weight was $8 \mathrm{lb} .14 \mathrm{oz}$. Present weight, at age 1 month, is $11 \mathrm{lb}$. The baby suffers from no dyspepsia, indigestion or diarrhoea of any sort. Motions are normal, and she appears to be a very good baby. The mother's diet is a normal one (and was so before the sample containing the very high fat content was taken). She does not like fat foods, takes 1 pint of milk a day only, very little butter and very little margarine. She had not taken anything special before the first sample was taken. She is a woman of average build, and has had three children, all breast fed.'

An even more exceptional example of high fat content in another mother was as follows:

\begin{tabular}{|c|c|c|c|}
\hline pril 22, 1950 & & & Total \\
\hline da) & 12 . & & \\
\hline
\end{tabular}

The same mother produced a further sample with the following result:
Mrs. W.
$9 \cdot 68$
9:05
$18 \cdot 73 \%$

Here, as in the other case, no disturbance was noticed in the digestion of the baby.

I give one further illustration of extreme variation in the fat content in an individual mother. This was the case of Mrs. T.:

October 6, 1950

$\begin{array}{lccc} & \text { Fat } & \text { Non-fatty Solids } & \text { Solids } \\ \text { Mrs. T. (No. 1) } & 1 \cdot 20 & 8 \cdot 81 & 10 \cdot 01 \% \\ \text { Mrs. T. (No. 2) } & 7 \cdot 82 & 8 \cdot 21 & 16 \cdot 03 \%\end{array}$

Here again the baby seemed to be unaware of these wide variations in his diet, and seemed to be as happy after a feed of milk containing $1 \cdot 20 \%$ as after one containing $7 \cdot 81 \%$ fat. Examples of these wide variations, both as between one mother and another and even in the milk from the same mother could be multiplied almost indefinitely.

The highest fat content in the Cardiff series was as follows:

$$
\begin{aligned}
& \text { November 15, } 1948 \\
& \text { Total }
\end{aligned}
$$

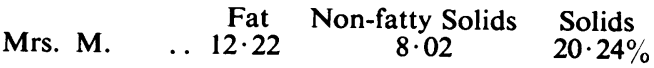

The infant suckling from this mother, like the others in the Cardiff series, exhibited no symptoms of gastric disturbance, yet Hutchison and Mottram (1936) say that a milk which contains more than 
$6 \frac{1}{2} \%$ of fat may always be expected to produce vomiting and diarrhoea.

The Cardiff milk donors are selected from maternity wards which deal with more than half the total confinements in the city every year. They represent a fair cross section of the income group involved and therefore of the variations in nutritional intake that may be found in any typical urban community. Against this background and against the clinical report quoted above, should be set the series of Cardiff human milk analyses which seem to discount many of the earlier findings according to which diet affects fat content of human milk, but which agree with the conclusion of Kon and Maw son (1950) that "no consistent variation in the fat content of (human) milk was observed between the third and 24th weeks of lactation.'

A number of series of analyses has been published in which the variations in composition of human milk with the stage of lactation have been noted by Elsdon and Walker (1942). The consensus of opinion, including Hutchison and Mottram (1936), but with the doubtful exception of Kon and Mawson (1950), seems to have been that the percentage of fat increases as the lactation advances. The Cardiff analyses do not support this opinion, as is shown by the following results (Table 1) taken at random; they happen to be the latest (May 8, 1951) of the routine samples taken at the human milk bank.

TABle 1

Cardiff Analyses of Fat Content of human milk

\begin{tabular}{ll|c|c|c|c}
\hline Mark & $\begin{array}{c}\text { Period of } \\
\text { Lactation }\end{array}$ & Fat & $\begin{array}{c}\text { Non-fatty } \\
\text { Solids }\end{array}$ & $\begin{array}{c}\text { Total } \\
\text { Solids } \\
(\%)\end{array}$ \\
\hline Mrs. H. & $\ldots$ & 6 weeks & $3 \cdot 30$ & $8 \cdot 49$ & $11 \cdot 79$ \\
\hline Mrs. T & $\ldots$ & 16 weeks & $5 \cdot 74$ & $8 \cdot 47$ & $14 \cdot 21$ \\
\hline Mrs. B & $\ldots$ & 20 weeks & $2 \cdot 51$ & $8 \cdot 66$ & $11 \cdot 17$ \\
\hline Mrs. C & $\ldots$ & 12 weeks & $2 \cdot 63$ & $8 \cdot 51$ & $11 \cdot 14$ \\
\hline Mrs. K & $\ldots$ & 4 weeks & $5 \cdot 27$ & $8 \cdot 63$ & 13.90 \\
\hline Mrs. B & $\ldots$ & 20 weeks & $3 \cdot 23$ & $8 \cdot 73$ & $11 \cdot 96$ \\
\hline Mrs. T & $\ldots$ & 20 weeks & $3 \cdot 67$ & $8 \cdot 57$ & $12 \cdot 24$ \\
\hline Mrs. S & $\ldots$ & 4 weeks & $3 \cdot 82$ & $8 \cdot 53$ & $12 \cdot 35$ \\
\hline Mrs. W & $\ldots$ & 24 weeks & $2 \cdot 70$ & $8 \cdot 42$ & $11 \cdot 12$ \\
\hline
\end{tabular}

Waller (1943) has shown that the fore milk in the first breast has a relatively lower fat content $(2 \cdot 7$ to $3.4 \%$ ), whereas the hind milk contained 7.0 to $7 \cdot 6 \%$. In the second breast, the fore milk con- tained $4 \cdot 1$ to $4.9 \%$, whereas the hind milk in this breast contained $6 \cdot 3$ to $6 \cdot 8 \%$. Other writers have stressed the importance of getting a full expression of human milk before placing any importance on analytical results.

In relation to these warnings and to Waller's findings, it should be emphasized that the Cardiff human milk donors are all well trained and experienced in expressing the milk fully from their breasts, and that most of them feed their babies first before expressing the milk that is left over. A few of them, whose milk flows exceptionally freely, on medical advice express an ounce before feeding their babies, and then express the rest after that; but since the milk they express in 24 hours is all pooled, and the sample for that mother taken from her pooled 24 hours' supply, the argument is hardly affected.

In the field of animal husbandry there has of late been something of an outcry about the decline in the composition of cow's milk, a decline which is said to be due to an increase in the number of dairy herds that are composed of cows producing quantity milk rather than quality milk. Some of these cows, it is said, produce milk of a fat content consistently below the relatively low standard of the Sale of Milk Regulations (1939), i.e. 3·0\%.

Thorpe's Dictionary of Applied Chemistry (1947) gives the fat content of the milk of various breeds of cows for the years ending October, 1936, and October, 1937 (Table 2).

TABLE 2

Percentage Fat Content of Milk of Various Breeds of Cow

\begin{tabular}{|c|c|c|}
\hline Breed & $\begin{array}{r}\text { Year ending } \\
\text { October, } 1936\end{array}$ & $\begin{array}{l}\text { Year ending } \\
\text { October, } 1937\end{array}$ \\
\hline Ayrshire .. & $3 \cdot 78$ & $3 \cdot 81$ \\
\hline British Friesian .. & $3 \cdot 26$ & $3 \cdot 29$ \\
\hline Guernsey & $4 \cdot 61$ & $4 \cdot 61$ \\
\hline Jersey $\quad .$. & $5 \cdot 04$ & $5 \cdot 05$ \\
\hline Lincoln Red & $3 \cdot 62$ & $3 \cdot 72$ \\
\hline Red Poll & $3 \cdot 62$ & $3 \cdot 64$ \\
\hline Shorthorn & $3 \cdot 58$ & $3 \cdot 62$ \\
\hline
\end{tabular}

Most analysts seem to agree that in respect of cow's milk it is generally true to say that the larger the quantity of milk produced the lower the fat content. 
Enquiries were made at the Cardiff Human Milk Bank as to whether any 'breeds ' or types of nursing mothers could be differentiated in the same way as has been done for cows, correlating their anthropological characteristics with their capabilities as quality milk producers. The answer was that although nothing definite had been observed with certainty along these lines, e.g. as to blonde or brunette, or even as to multipara or primipara, there was no doubt that the plentiful or copious milk yield came not, as might have been expected, from the big woman, but rather from the small dainty type.

Kon and Mawson (1950) reported that in general variations in fat content of human milk do not necessarily follow corresponding variations in milk yield.

The possibility that further research into anthropological characteristics of human milk producers may produce definite results leads to some interesting speculations.

Thus, when at last the business of living has been changed entirely from an art into a science, it may well happen that a young man looking for a suitable mate, especially if he be a paediatrician, not content with an exchange of pre-marital health certificates, will look further for a young lady of the 'Jersey' type.

Rowland (1951) has recently pointed out that almost certainly in all breeds of cows, the solids-not-fat content of recent years has shown an appreciable decline. Kon and Mawson (1950) claim that the levels of solids-not-fat observed in their study of human milk agree in general with those recorded in the literature, and remained constant during the three years (1942-45) of their investigations. The Cardiff figures agree in the main with those set out by Kon and Mawson (1950), not only in actual levels, but also as regards their constancy by comparison with variations in fat content in the same sample analyses. The relative constancy in solids-not-fat content compared with wide variations in fat content in the same milk samples tends to raise doubts as to the importance of fat as a nutrient, and suggests that more attention should be paid by nutritionists to the solids-not-fat content of human milk, especially the protein and ash value and the albumin and casein ratio.

The average composition of all milk samples taken from the Cardiff Human Milk Bank since it started in 1947 is as follows:

$\begin{array}{cccc}\text { No. of Samples } & \text { Fat } & \text { Solids-not-fat } & \text { Total Solids } \\ \mathbf{3 7 1} & \mathbf{9} \cdot 90 & \begin{array}{c}\mathbf{9} \cdot 00 \\ 12 \cdot 90 \%\end{array}\end{array}$

Table 3 shows other averages that have been obtained for human milk.
TABLE 3

Averages for Human Milk

\begin{tabular}{|c|c|c|c|c|}
\hline Observer & $\begin{array}{l}\text { No. of } \\
\text { Samples }\end{array}$ & Fat & $\begin{array}{l}\text { Solids } \\
\text { (not fat) }\end{array}$ & $\begin{array}{r}\text { Total } \\
\text { Solids }\end{array}$ \\
\hline $\begin{array}{l}\text { Elsdon }(1916) \\
\text { Elsdon }(1928) \\
\text { Gardner and Fox } \\
\quad \text { (1925) } \\
\text { Myers (1929) } \\
\text { Leeds (1942) }\end{array}$ & $\begin{array}{c}79 \\
529 \\
? \\
? \\
86 \\
?\end{array}$ & $\begin{array}{l}3 \cdot 28 \\
3 \cdot 3 \\
3 \cdot 7 \\
3 \cdot 95 \\
4 \cdot 16\end{array}$ & $\begin{array}{c}8 \cdot 7 \\
11 \cdot 70 \\
9 \cdot 15\end{array}$ & $\begin{array}{l}\% \\
11 \cdot 78 \\
12 \cdot 1\end{array}$ \\
\hline
\end{tabular}

\section{Conclusion}

This paper is not the report of any planned investigation. It contains no 'mean values' or 'standard deviations'. It represents simply an account of the working of the Cardiff Human Milk Bank, and of reflections aroused by studying the reports of chemical analyses carried out as a routine on samples of human milk taken on their way to be pooled and pasteurized at the Milk Bank. The Cardiff analyses have been compared with those made elsewhere. It is suggested that there may be advantages in basing studies of the nutritional and other properties of human milk upon analyses of samples taken at human milk banks from mothers who have been trained to express their surplus milk as a routine, and who are not conscious that they are taking part in any ad hoc investigation. No question of nervousness preventing a complete 'let down' of their milk could arise in the mothers giving natural supplies of milk to a milk bank as it could in mothers volunteering to take part in an ad hoc investigation. Further, the case histories of mothers supplying a milk bank should be available, though again indirectly and probably therefore more accurately, in the fullest possible form, going back to the ante-natal clinic and hospital confinement records, post-natal records and results of observations by health visitors and the milk bank sister in routine visits to the homes. By planning an exhaustive investigation through the use of such records and such observers, the whole system being in the very nature of things more detached than investigations of the kind reported by Kon and Mawson (1950), it should be possible to obtain some striking results. Most observers in the past have felt a sense of frustration because of the difficulty of getting adequate clinical data for full correlation with chemical analyses. Thus when Hilditch and Meara (1944) tell us that human milk fat in regard to its component acids, has more resemblance to a typical margarine fat-blend (i.e. characteristics of coconut and other 'nut oils') than to a butter fat, 
this is very interesting but what is its clinical significance? Is that why, seemingly, infants can stand such wide variation in human milk fat content without any gastro-intestinal disturbances? These and other questions could probably be answered by an investigation carefully planned in great detail by say, a young research fellow in co-operation with the clinicians and the chemists associated with a human milk bank, and, of course, a university statistician. The material is there, any amount of it, only waiting to be used. We have now three large human milk banks in this country, the first at Queen Charlotte's Hospital, the second at Cardiff, and a third has just been opened at Birmingham.

I am indebted to the Department of Child Health of the Welsh National School of Medicine for the clinical reports, and for help in the chemical studies I owe much to Mr. Stanley Dixon, Cardiff Public Analyst, and to
Dr. J. G. Davis, Director (Technical) of the Express Dairy Company Ltd.

\section{BIBLIOGRAPHY}

Elsdon, G. D. (1916). Analyst, 41, 74. (1928). Ibid., 53, 78.

—, and Walker, G. H. (1942). 'Richmond's Dairy Chemistry,'4th ed. London.

Gardner, J. A., and Fox, F. W. (1925). Practitioner, 1,153

Hilditch, T. P., and Meara, M. L. (1944). Biochem. J., $38,29,437$.

Hutchison, R. and Mottram, V. H. (1936). 'Food and the Principles of Dietetics,' 8th ed. London.

Kon, S. K., and Mawson, E. H. (1950). Spec. Rep. Ser. med. Res. Coun., Lond., No. 269.

Leeds. Cited in 'Richmond's Dairy Chemistry,' 4th ed., rev. by G. D. Elsdon and G. H. Walker, p. 64 .

Myers, B. (1929). Brit. J. Child. Dis., 24, 249; Chem. Abs., 1929, 23, 3265.

Rowland, S. J. (1951). J. roy. sanit. Inst., 71, 255.

Waller, H. K. (1943). Lancet, 1, 69. 